\title{
Investigating the Performance of a Ship by Matching the Stern Hull Form to Propeller and Engine Power
}

\author{
Andi Dian Eka Anggriani ${ }^{\mathrm{a}, *}$, Suandar Baso ${ }^{\mathrm{b}}$ \\ aDepartment of Naval Architecture, Faculty of Engineering, Hasanuddin University. Email: a.dianeka@unhas.ac.id \\ ${ }^{b}$ Department of Naval Architecture, Faculty of Engineering, Hasanuddin University. Email: s.baso@eng.unhas.ac.id
}

\begin{abstract}
Designing the form of the ship stern hull could have some impacts on the efficiency of ship propeller and the requirement of the ship speed. Therefore, stern hull form of a ship matched to its propeller and engine power is important consideration in preliminary ship design stage. The main objective of this study is to investigate ship performance by matching the stern hull shape to the propeller diameter and engine power toward high speed. This study was conducted by free running model test and Maxsurf Resistance application. The stern forms were employed U-shape and V-shape. In addition, the fixed pitch propeller (FPP) with three blades was used and the diameter is varied into three sizes $0.032 \mathrm{~m}, 0.040 \mathrm{~m}$, and $0.048 \mathrm{~m}$. The results show the increase of propeller diameter increases model's speed for both U-shape and V-shape stern and the effect of the propeller diameter on the speed could be described by using the equations of second-order polynomial. The optimum propeller diameter could be determined taking into account stern hull form, stern shape, tip clearance, and proper speed where then propeller diameter related to draft is given by $0.79 \mathrm{~T}$ with tip clearance $10 \% \mathrm{Dp}$ for both $\mathrm{U}$-shape and V-shape. The ship resistances of U-shape stern at Fr 0.221 and V-shape at 0.208 are obtained approximately $89.797 \mathrm{KN}$ and 77.10 $\mathrm{KN}$ respectively. Furthermore, the powers of ship for both U-shape and V-shape at those Fr are obtained 904,374 KW and 726,807 KW respectively. Finally, the best stern hull form matched to propeller diameter and engine power is selected and given by U-shape stern.
\end{abstract}

Keywords: Stern hull form ; U-shape ; V-shape

\section{Introduction}

All ship owners need the good performance for their ship in actual sea and the one of aspect is the proper service speed. This impacts on cost and time operation. Therefore, a ship must be design properly to achieve a proper service speed. Correspondingly, some parameters of ship hydrodynamic must be investigated and considered completely associated with hull form, engine power, and propulsion system.

Although, a stern form of a ship design is obtained in good shape, however the proper determination of main engine power and propeller diameter are also important things in ship design. This must be noted that a ship hull form should match to propulsion system. Particularly in the stern form, the shape of stern contour is mostly related with propulsion performance, therefore a stern form of a ship must be matched to propeller diameter as well. For stern form design, a number of factors such as hydrodynamic efficiency, construction simplicity and flow patterns must be considered. The design of ship stern shape must ensure uniform flow of water around the hull and good hull efficiency coefficient and then these indicate on that mitigate the stern waves and improve the flow into the propeller.

Some studies related with hull form of a ship matched to propulsion system have been conducted widely.

${ }^{*}$ Corresponding author. Tel.: +6285255325548

Jalan Poros Malino km.6 Gowa

Sulawesi Selatan 92171
Stapersma and Woud [1] discussed the basic matching problem of a propulsion engine to the propulsor and its influences and they also applied their calculation method to evaluate design and off design conditions. Ukon et al. [2] developed the ship hulls and optimum propellers to concretely solve some serious hydrodynamic problems on a high-speed and high-powered ship with a large diameter single screw propeller. Lin et al. [3] proposed a process to design ship-engine-propeller simultaneous matching where the ship-propeller subsystem and the enginepropeller subsystem in which relationships between rotational speed of the propeller and advancing speed that were expressed $\mathrm{N}-\mathrm{V}$ curves. Ogar et al. [4] proposed the design analysis to use for optimal matching of controllable pitch propeller to the hull and diesel engine. In order to make the wake field more uniform, the stern frame from above the shaft line was shifted to the stem and the stern bulb sectional area was increased and the gravity center of the area was made lower. Ren et al. [5] proposed a procedure development of the combination of the system matching theory and Energy Efficiency Design Index (EEDI) calculation, which can provide the matching results of ship-engine-propeller as well as the corresponding EEDI value. Nurhadi et al. [6] studied engine propeller matching and discussed EPM on a high speed vessel that uses Gawn series propeller type.

The stern of a ship has several forms or shapes such as $\mathrm{V}$-shape, the U-shape, transom etc. Each shape has 
individually its own advantages and disadvantages. The choice of the shape of the top side stern section should be decided on the basis of Froude number. The design hull form of a ship taking into account proper speed have been studied such as Lu et al. [7] proposed an innovative methodology of synchronous local optimization of ship bow and stern hull form considering the whole ship speed range. Ghasemi and Zakerdoost [8] proposed design methodology that represents a comprehensive approach to optimize the hull-propeller system simultaneously wherein the well-known evolutionary algorithm based on NSGA-II was employed to handle the multi-objective problems, where the main propeller and hull coefficients are the unknown and are considered as design variables.

The different types of propellers are classified by blade number and blade pitch. However, the number of propeller blade has little agreement for the best options. The effectiveness of a propeller depends upon several factors, but diameter is one of the most important.

Johannsen [9] investigated the performance of threebladed propeller with varying diameters for the ship. For all variants the radial pitch and camber distribution was reevaluated to achieve best wake adaptation and the threebladed propeller gained up to $3.5 \%$ in power requirement.

Based on the explanation above, this study describes the container ship performance which was investigated by matching the stern hull form to propeller and engine power. Then, the investigation was conducted by free running model test where the U-shape and V-shape of stern form were matched to varied propeller size and engine power based on resistance results generated by $\mathrm{U}$ shape and V-shape. The resistance of ship was predicted by using Maxsurf Resistance [10].

\section{Methods}

Here, the ship performance was investigated by conducting the free running model test and using Maxsurf Resistance [10]. The stern shapes were matched to varied propeller diameters and engine power. Then, this study steps are shown in Fig. 1.

Ship type which was employed in this study is container. Then, ship main particulars are provided in Table 1 and body lines plan are shown in Fig. 2. This ship has previously U-shape in the stern part along hull ship which has a body lines plan as shown in Fig. 2a. Furthermore, it was re-designed becoming V-shape particularly in stern part (in section areas 1 to 3 ) and the body lines plan is shown in Fig. 2b. While re-design process, the hydrostatic parameters were verified and then they must be similar as provided in Table 2. The 3dimensional shape both $\mathrm{U}$-shape and $\mathrm{V}$-shape is shown in Fig. 3. In addition, ship models were made with scale 1:100 and the ship models for both shapes are shown in Fig. 4. In addition, the fixed pitch propeller (FPP) with three blades was used and the propeller diameter (Dp) is varied into three sizes $32 \mathrm{~mm}(0.032 \mathrm{~m}), 40 \mathrm{~mm}(0.040$ $\mathrm{m})$, and $48 \mathrm{~mm}(0.048 \mathrm{~m})$ as shown in Fig. 5.

The purpose of free running model test is to obtain model speed with varieties of stern shape and propeller diameters. Free running model test was conducted at towing tank, Ship Hydrodynamic Laboratory, Naval
Architecture Department, Faculty Engineering, Hasanuddin University. The towing tank sizes are $60 \mathrm{~m}$ in length, $4 \mathrm{~m}$ in width, and $4 \mathrm{~m}$ in depth. In order to measure model speed, the model was run freely along 25 meters at towing tank. For test set-up, some tools and devices were provided such as electric motor (1400KV), servo motor (Torque $15 \mathrm{~kg} . \mathrm{cm}$ ), electronic speed control (ESC), rudder, universal joint (dia. in $3.17 \mathrm{~mm}$, out $4 \mathrm{~mm}$ ), radio control remote $(2.4 \mathrm{GHz})$, shaft (dia. $4 \mathrm{~mm})$, stopwatch, tachometer, battery (4000mAh). The tools and devices are shown in Fig. 6 and they were attached and installed on models. The revolution per minutes (RPM) in shaft was measured by using tachometer that is 1088 .

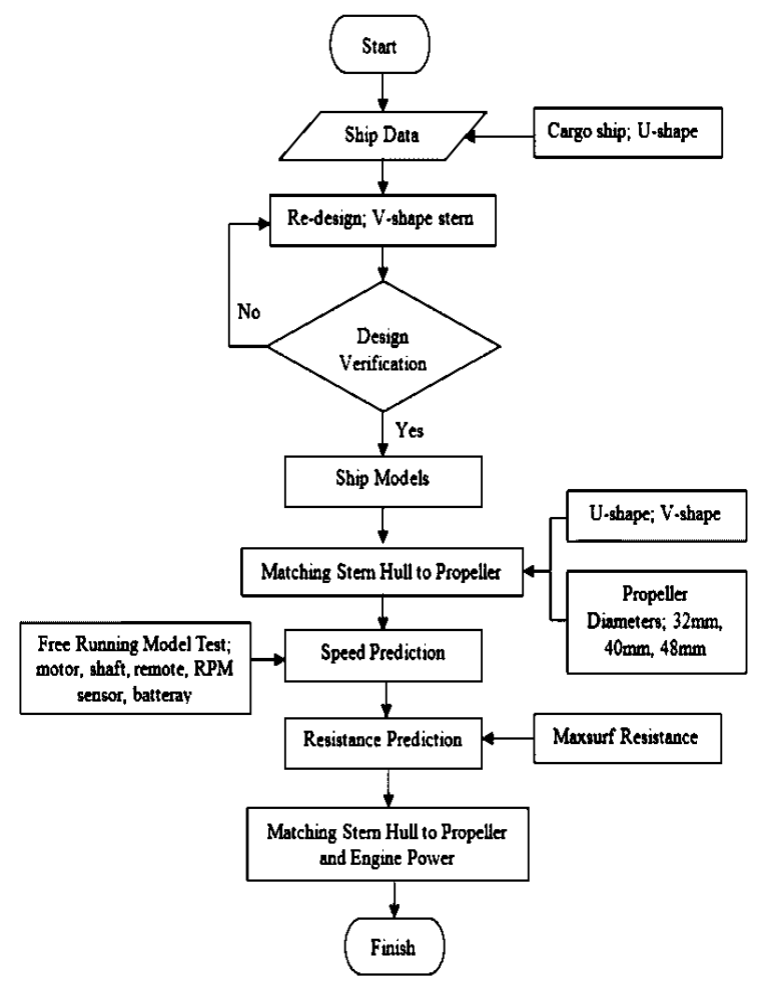

Figure 1. The systematical study steps

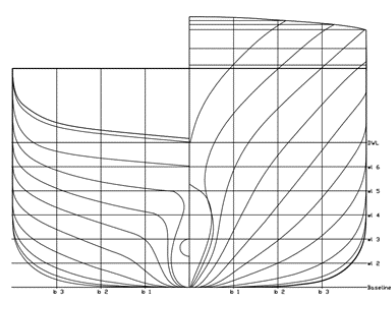

a

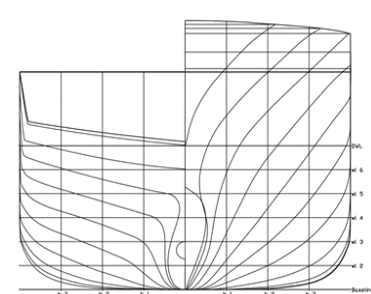

$\mathrm{b}$
Figure 2. Body lines plan; a). U-shape, b). V-shape
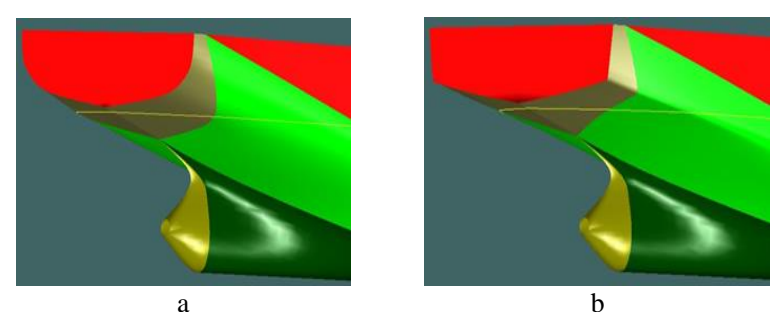

Figure 3. The 3-dimensional stern hull form; a). U-shape, b). V-shape 


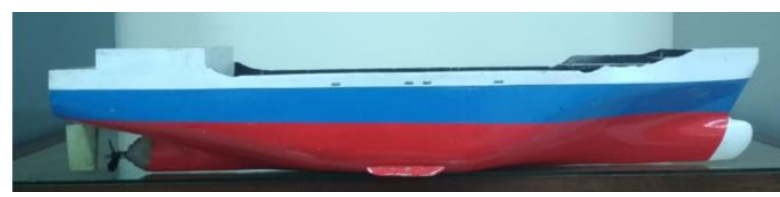

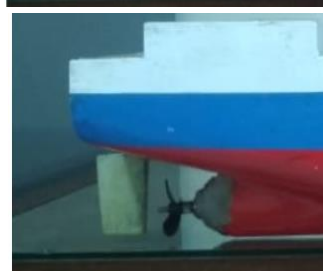

a

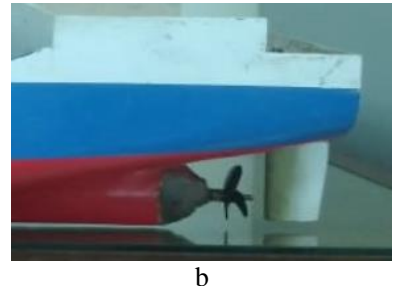

Figure 4. Ship models; Stern form a). U-shape, b). V-shape

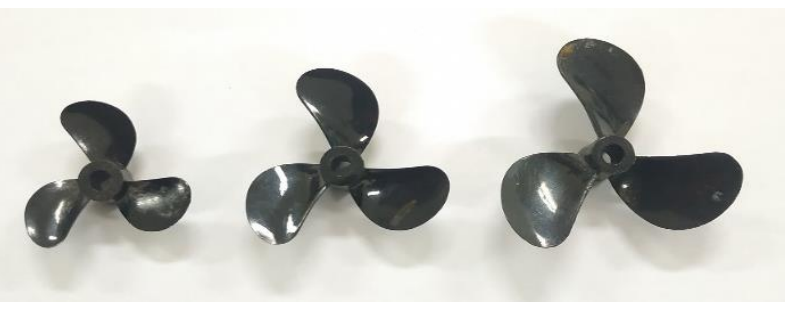

Figure 5. Propeller models FPP; Diameter a). $32 \mathrm{~mm}, \mathrm{~b}) .40 \mathrm{~mm}, \mathrm{c}) .48 \mathrm{~mm}$

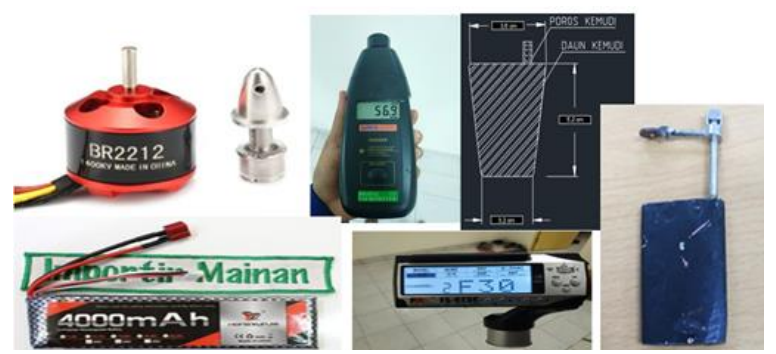

Figure 6. Tools and devices for the set-up of free running model test

Table 1. Ship main particulars

\begin{tabular}{lc}
\hline \multicolumn{1}{c}{ Description } & Value \\
\hline Lenght overall (Loa) & $80.00 \mathrm{~m}$ \\
Length between perpendiculars (Lbp) & $74.43 \mathrm{~m}$ \\
Length water line (Lwl) & $76.29 \mathrm{~m}$ \\
Breath (B) & $15.00 \mathrm{~m}$ \\
Depth (H) & $9.24 \mathrm{~m}$ \\
Draft (T) & $6.15 \mathrm{~m}$ \\
Block coefficient & 0.602 \\
Displacement & $4343 \mathrm{ton}$ \\
\hline
\end{tabular}

Meanwhile, ship resistances for both shapes were predicted by using software application Maxsurf Resistance. The propulsive coefficient is overall efficiency that are propulsor efficiency, hull efficiency, relative rotative efficiency, appendage coefficient and the shaft transmission losses. Then, the efficiency was specified by assuming total efficiency for container ship, the same efficiency is used to calculate the power over the whole speed range. Nevertheless, wave contours for both shapes were predicted as well to predicted water flow particularly in stern region.
Table 2. The hydrostatic parameters after re-designed process particularly in the stern part

\begin{tabular}{lcc}
\hline \multirow{2}{*}{ Description } & \multicolumn{2}{c}{ Value } \\
\cline { 2 - 3 } & U-shape & V-shape \\
\hline Displacement (ton) & 4343 & 4343 \\
Displaced volume (m $\left.{ }^{3}\right)$ & 4237.02 & 4237.02 \\
Immersed depth (m) & 6.15 & 6.15 \\
Water line length (m) & 76.29 & 76.29 \\
Beam max extents on water line (m) & 15.00 & 15.00 \\
Prismatic coeff. (Cp) & 0.628 & 0.627 \\
Block coeff. (Cb) & 0.602 & 0.602 \\
Max section area coeff. (Cm) & 0.959 & 0.961 \\
Water plane area coeff. (Cwp) & 0.84 & 0.838 \\
$\begin{array}{l}\text { Length centre bouyancy/LCB (m) from } \\
\text { after peak point }\end{array}$ & 37.24 & 37.30 \\
Keel to bouyancy point/KB (m) & 35.24 & 35.17 \\
\hline
\end{tabular}

Accordingly, stern hull forms which were matched to propeller and engine power were obtained based on investigation results. Regardless, this study investigated the best selected stern shape as well.

\section{Results and Discussion}

The free running model test was successfully performed at towing tank as show in Fig. 7. The test was performed in keeping the straight forward movement only. The revolution per minutes (RPM) of model's shaft without attached propeller was measured by using tachometer and then it was obtained 1088. This RPM was measured in full power of electric motor. In this test, full power was used each test. Then, the shaft's RPM was in the same condition with other tests where test was performed three times on each case. The investigation of speed characterized by Froude number (Fr) in matching stern shapes to varied propeller diameters was conducted. The test data for both stern hull form (U-shape and Vshape) and three propeller diameters were obtained as provided in Table 3 . The increase of propeller diameter increases model's speed for both stern forms. The increase of model's speed is significantly high from propeller diameter $0.032 \mathrm{~m}$ to $0.040 \mathrm{~m}$ and then it tends to increase slightly from propeller diameter $0.040 \mathrm{~m}$ to $0.048 \mathrm{~m}$ as shown in Fig. 7. The increase speeds from propeller diameter $0.032 \mathrm{~m}$ to $0.040 \mathrm{~m}$ and then $0.040 \mathrm{~m}$ to $0.048 \mathrm{~m}$ are approximately $18.6 \%$ and $10.3 \%$ respectively.

Meanwhile, Figure 8 shows the trendlines of the relation between propeller diameters and Froude number (Fr) in matching to stern hull forms by using the equations of second-order polynomial with R-squared value (R) 1.0. This equation describes the propeller diameter affects significantly on the speed. By using the trendlines derived by those equations as shown in Fig. 9, the peak speeds for U-shape and V-shape are at Fr 0.227 and 0.212 . for propeller diameter $0.058 \mathrm{~m}$ and $0.056 \mathrm{~m}$ respectively. 


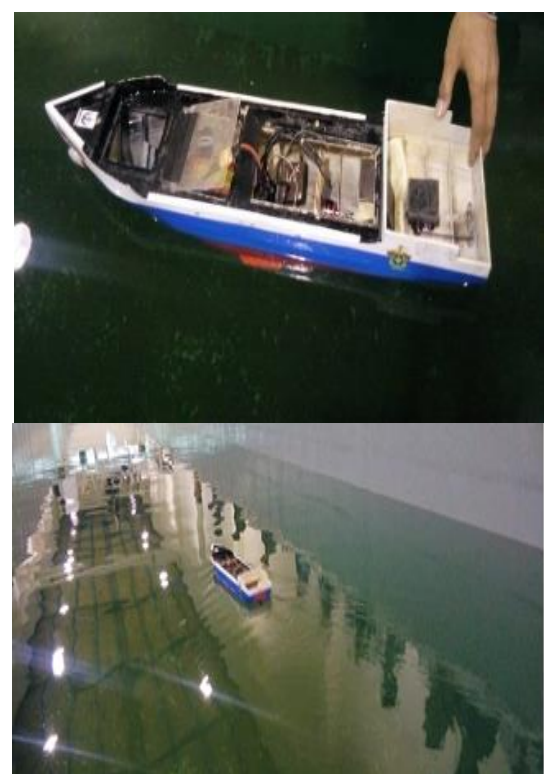

Figure 7. The free running model test performed at towing tank

Table 3. The average speed model achieved by matching stern shapes to varied propeller diameters

\begin{tabular}{ccc}
\hline Stern Form & Propeller Dia. $(\mathbf{m})$ & $\begin{array}{c}\text { Averaged Speed } \\
(\mathbf{m} / \mathbf{s e c} .)\end{array}$ \\
\hline \multirow{3}{*}{ U-shape stern } & 0.032 & 0.431 \\
& 0.040 & 0.530 \\
V-shape stern & 0.048 & 0.593 \\
& 0.032 & 0.411 \\
& 0.040 & 0.505 \\
& 0.048 & 0.561 \\
\hline
\end{tabular}

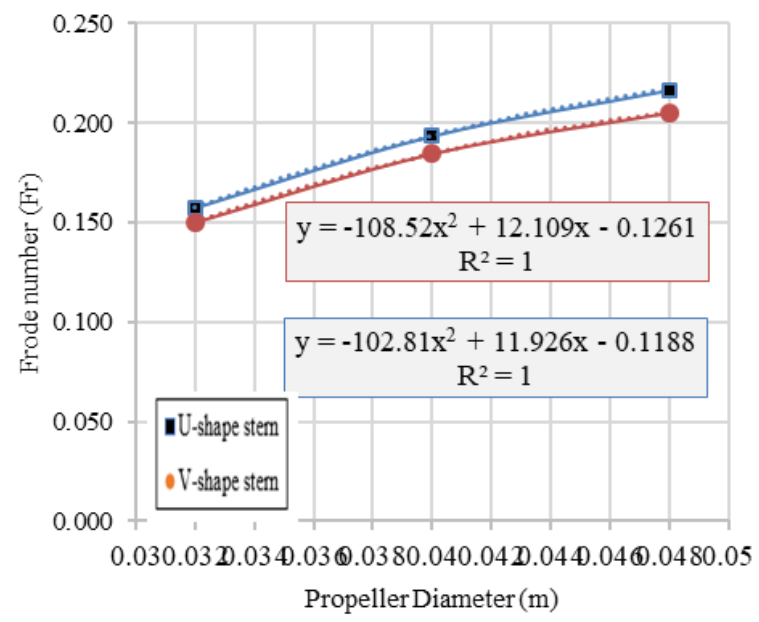

Figure 8 . The relation between propeller diameter and Fr for both stern form U-shape and V-shape

The speed decreases gradually after reaching the peak speed and this is because of the high impact on hull pressure induced by the interaction between stern form, propeller and wake inflow and outflow. This impact is similar on both stern hull forms which were matched to varied propeller diameters.

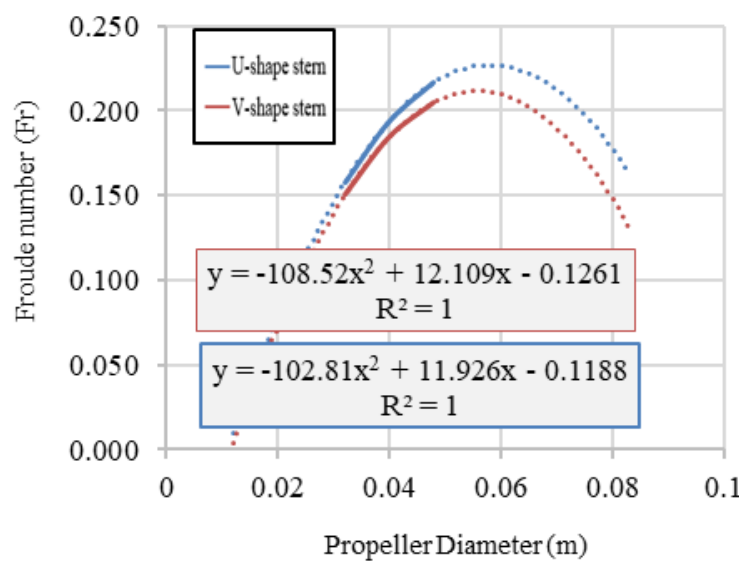

Figure 9. The relation between propeller diameter and Fr given by the quadratic function

In determining the propeller diameter, the propeller diameter could be obtained based on open water tests of systematic propeller series, numerical simulation, computational fluid dynamic (CFD), statistical analysis, or empirical method. For a simple method, a propeller diameter of a ship is determined as given by 0.70 of design draft and it was adopted as a standard in the LCB and geometrical variation series [11]. The approximations of the propeller diameter/design draft ratio $(\mathrm{d} / \mathrm{T})$ for container ship can be given 0.74 [12]. Also, the approximations of diameter propeller can be used as function of the maximum draft given by statistical analysis that is 0.623 Tmax -0.16 by Kristensen and Lutzen [13].

As defined on previous explanations, the maximum speed could be determined in this study based on function of propeller diameter and draft. Then, it is given by the ratio of propeller and draft which is approximately 0.94 and 0.91 for U-shape and V-shape respectively. However, the propeller diameter is not only depended on stern shape, propeller blade number, and maximum speed but also on stern design and propeller tip clearance.

Bensow and Gustafsson [14] investigated the clearances between the propeller tip and a generic hull with tunnel configuration with similar propeller diameter that were $0.7 \% \mathrm{Dp}, 5 \% \mathrm{Dp}$, and $20 \% \mathrm{Dp}$. Then, the predicted impact on hull pressure is very large, with the maximum amplitude differing an order of magnitude between the small clearance case and the one with normal clearance. Moreover, some practical rules use $10 \% \mathrm{Dp}$ to $30 \% \mathrm{Dp}$.

The small propeller tip clearance generates propellerhull vortex cavitation and vibration, in contrast high clearance have a little impact on propeller performance, however it is affected on low speed. Therefore, the wake dynamics is caused by propeller tip clearance. The wave contour along ship for both shapes at a few Froude number are shown in Fig. 10. The wave contour is resulted in different magnitude comparing between low and high Froude number. In addition, the wake induced by stern shape and propeller diameter in inflow and outflow region could be distinguished. The wake discrepancies between U-shape and V-shape at the same Fr seems slight as depicted in Fig. 11. 
Figure 12 shows stern hull form, propeller diameter and propeller tip clearance for both U-shape and V-shape. The propeller diameter which is $4.8 \mathrm{~m}$ (actual ship dimension) or $0.048 \mathrm{~m}$ (model dimension) has a propeller tip approximately $0.62 \mathrm{~m}$ (0.0062 $\mathrm{m}$ for model) according to stern hull design. Referring to this propeller tip clearance, it is given $12.9 \% \mathrm{Dp}$.

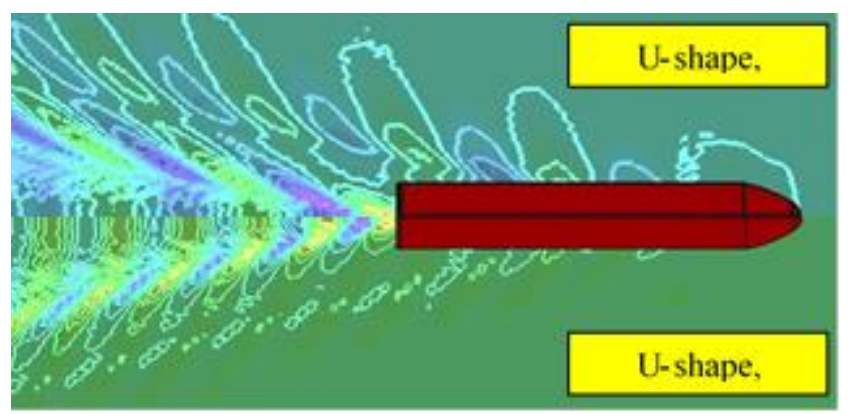

Top view

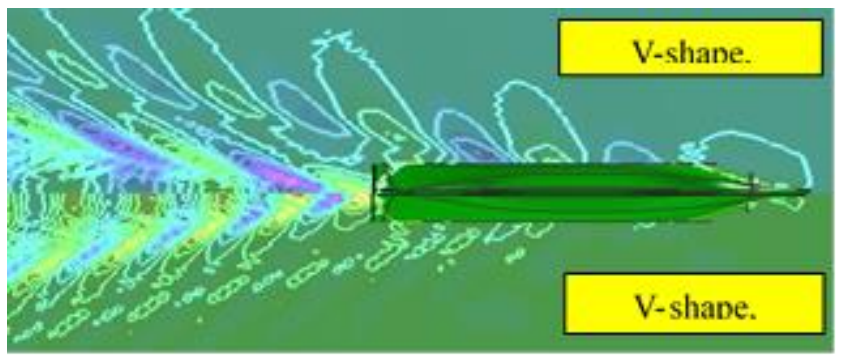

Bottom view

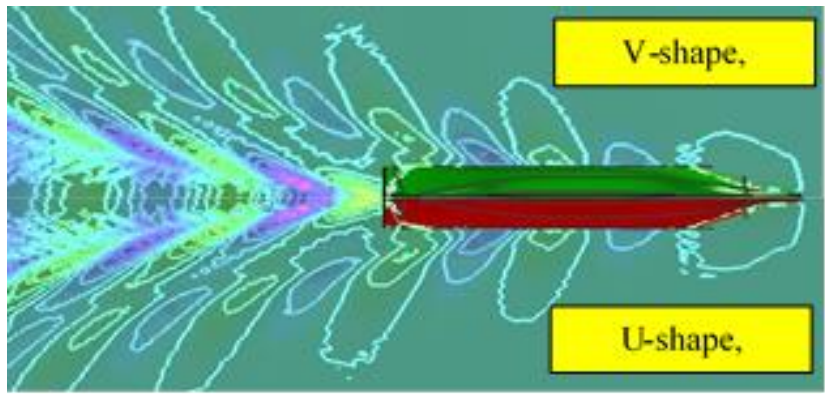

Bottom view

Figure 10. Wave contour along ship for both U-shape and V shape

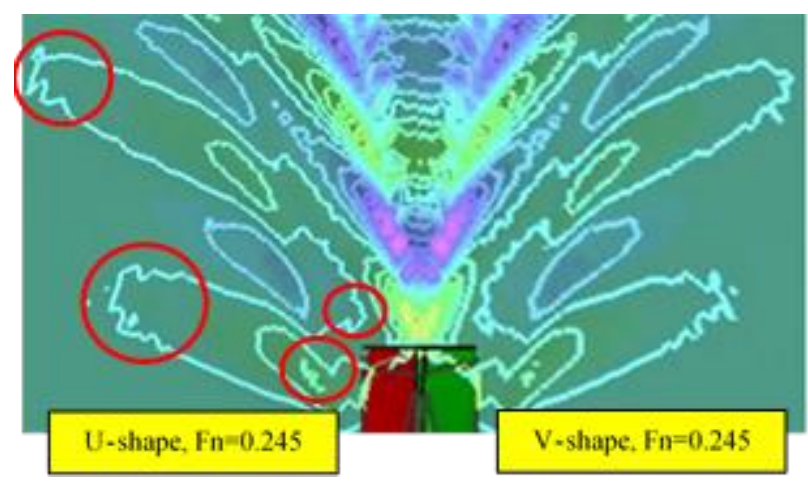

Figure 11. The discrepancies of wake surface between U-shape and V shape at $\mathrm{Fn}=0.245$

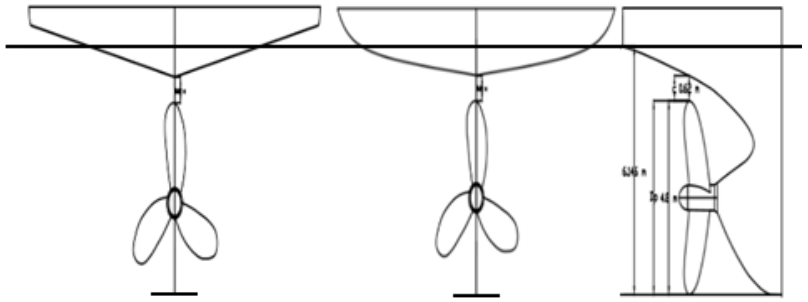

Figure 12. Stern hull forms and propeller tip clearance for both U-shape and V-shape

This must be noted that the determination of propeller diameter considers the stern hull design and propeller tip clearance although the greater propeller diameter it produces higher speed. Therefore, the optimum propeller diameter could be determined in this study taking into account stern hull form, stern shape, tip clearance, and proper speed where then propeller diameter related to draft is given by $0.79 \mathrm{~T}$ with tip clearance $10 \% \mathrm{Dp}$ for both Ushape and $\mathrm{V}$-shape. However, those propeller diameters produce in different speed (Fr) for both U-shape and Vshape that are approximately $0.221(11.69 \mathrm{Knot})$ and 0.208 (11 Knot) respectively.

The ship resistances for both U-shape and V-shape were obtained by using Maxsurf resistance application by using Holtrop method [15] as shown in Fig. 13. Here, these resistances are without propeller and rudder attachments and total efficiency was given 0.60. Based on Fig. 10, the higher ship is produced by U-shape comparing with $\mathrm{V}$ shape in the same resistance. The ship resistances of $U$ shape stern at Fr 0.221 and V-shape at 0.208 are obtained approximately $89.797 \mathrm{KN}$ and $77.10 \mathrm{KN}$ respectively. Furthermore, the powers of ship for both U-shape and Vshape at those Fr are obtained 904,374 KW and 726,807 KW respectively as shown in Fig. 14.

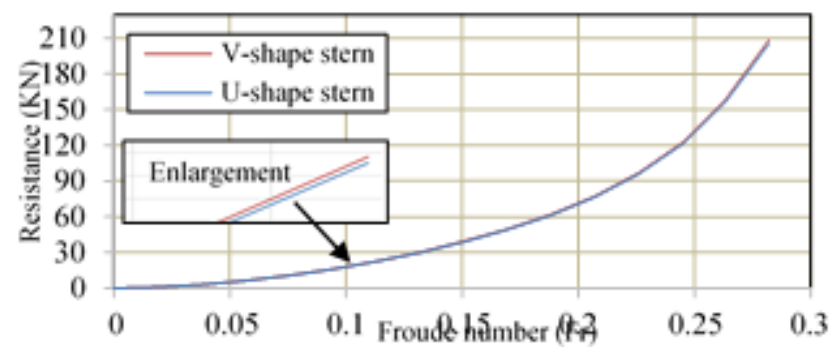

Figure 13. The ship resistances for both U-shape and V-shape

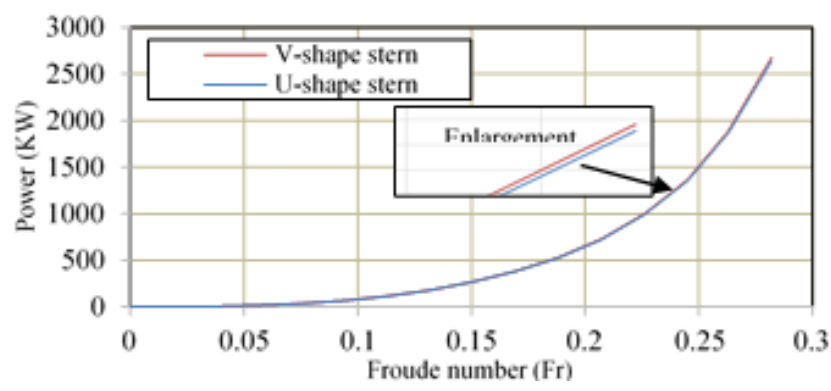

Figure 14. The ship engine power for both U-shape and V-shape 
Accordingly, the best stern hull form matched to propeller diameter and engine power is selected and obtained that is U-shape stern with suitable propeller diameter $0.79 \mathrm{~T}$, propeller tip clearance $10 \% \mathrm{Dp}$, engine power $904,374 \mathrm{KW}$, and propeller shaft $1088 \mathrm{RPM}$. This matching condition could be produced ship speed approximately 11.69 Knot or Fr 0.221 .

\section{Conclusions}

Herein the investigation of the performance of a ship by matching the stern hull form to propeller and engine power was successfully conducted and then the method could be proposed to implement in preliminary ship design.

The increase of propeller diameter increases model's speed for both U-shape and V-shape stern. the trendlines of the relation between propeller diameters and Froude number (Fr) in matching to stern hull forms by using the equations of second-order polynomial with R-squared value $(\mathrm{R})$ 1.0. The effect of the propeller diameter on the speed could be described by using the equations of secondorder polynomial. The peak speeds for U-shape and Vshape are at Fr 0.227 and 0.212 . for propeller diameter $0.058 \mathrm{~m}$ and $0.056 \mathrm{~m}$ respectively. The speed decreases gradually after reaching the peak speed and this is because of the high impact on hull pressure induced by the interaction between stern form, propeller and wake inflow and outflow.

This must be noted that the determination of propeller diameter considers the stern hull design The optimum propeller diameter could be determined in this study taking into account stern hull form, stern shape, tip clearance, and proper speed where then propeller diameter related to draft is given by $0.79 \mathrm{~T}$ with tip clearance $10 \% \mathrm{Dp}$ for both $\mathrm{U}$-shape and $\mathrm{V}$-shape. The ship resistances of U-shape stern at Fr 0.221 and V-shape at 0.208 are obtained approximately $89.797 \mathrm{KN}$ and 77.10 $\mathrm{KN}$ respectively. Furthermore, the powers of ship for both U-shape and V-shape at those Fr are obtained 904,374 KW and $726,807 \mathrm{KW}$ respectively. Finally, the best stern hull form matched to propeller diameter and engine power is selected and obtained that is U-shape stern with suitable propeller diameter $0.79 \mathrm{~T}$, propeller tip clearance $10 \% \mathrm{Dp}$, engine power $904,374 \mathrm{KW}$, and propeller shaft 1088 RPM.

\section{Acknowledgements}

We gratefully acknowledge to undergraduate students, Ship Hydrodynamic Laboratory, Naval Architecture Department, Engineering Faculty, Hasanuddin University namely Ardedi Yusuf and C.J.V. Sitorus who supported to perform experimental work for this research.

\section{References}

[1] D. Stapersma and H. Woud, "Matching propulsion engine with propulsor," J. Mar. Eng. Technol., 2005.

[2] Y. Ukon et al., "Research on Improvement of Propulsive Performance of a High-Speed Ship Equipped with a HighPowered Propeller," Natl. Marit. Res. Inst., vol. 8, no. 1, pp. 5182.

[3] S. Lin, J. Sun, and D. Xie, "Design of ship-engine-propeller simultaneous matching and development of a propeller and engine selecting system," in MARINE 2015 - Computational Methods in Marine Engineering VI, 2015.

[4] O. B. Ogar, S. Nitonye, and I. John-Hope, "Design Analysis and Optimal Matching of a Controllable Pitch Propeller to the Hull and Diesel Engine of a CODOG System," J. Power Energy Eng., 2018.

[5] H. Ren, Y. Ding, and C. Sui, "Influence of EEDI (Energy efficiency design index) on ship-engine-propeller matching," $J$. Mar. Sci. Eng., 2019.

[6] N. Nurhadi, H. Zen, and S. Sumarsono, "Study of Engine Propeller Matching for High-Speed Vessel with Gawn Series Propeller," EPI Int. J. Eng., 2018.

[7] Y. Lu, X. Chang, X. Yin, and Z. Li, "Hydrodynamic Design Study on Ship Bow and Stern Hull Form Synchronous Optimization Covering Whole Speeds Range," Math. Probl. Eng., 2019.

[8] H. Ghassemi and H. Zakerdoost, "Ship hull-propeller system optimization based on the multi-objective evolutionary algorithm," Proc. Inst. Mech. Eng. Part C J. Mech. Eng. Sci., 2017.

[9] Christian Johannsen, "Three blades for reduced fuel consumption A new generation of optimum performance propellers for tanker and bulker," HSVA Newswave, Hamburg, p. 1, 2007.

[10] Maxsurf, "Maxsurf Resistance." Bentley Software, 2014.

[11] Todd F.H, Series 60 Methodical Experiments with Models of Single-screw Merchant Ships. 1963

[12] MAN Diesel \&Turbo, "Basic Principles of Ship Propulsion," 2011.

[13] H. O. Kristensen and M. Lützen, "Prediction of resistance and propulsion power of ships," Proj. no. 2010-56, Emiss., 2012.

[14] Rickard E Bensow and Robert Gustafsson, "Effect of Propeller Tip Clearance on Hull Pressure Pulses," in 5th International Symposium on Marine Propulsors, 2017.

[15] J. Holtrop and G. G. J. Mennen, "APPROXIMATE POWER PREDICTION METHOD.," in International Shipbuilding Progress, 1982. 